\title{
A COMPARATIVE STUDY OF SUB-ARACHNOID BLOCK USING INTRATHECAL BUPIVACAINE AND INTRATHECAL BUPIVACAINE WITH LOW DOSE OF EITHER CLONIDINE OR DEXMEDETOMIDINE IN ABDOMINAL HYSTERECTOMY
}

\author{
Subhash Ranjan Das ${ }^{1}$, Ranjit Reang ${ }^{2}$, Joydeep Debnath ${ }^{3}$ \\ ${ }^{1}$ Associate Professor, Department of Anaesthesiology, AGMC, Agartala. \\ ${ }^{2}$ Senior Resident, Department of Anaesthesiology, AGMC, Agartala. \\ ${ }^{3}$ Senior Resident, Department of Anaesthesiology, AGMC, Agartala.
}

\section{ABSTRACT}

\section{BACKGROUND}

Subarachnoid block has gained popularity in the surgeries of lower abdomen and lower limbs because of its ease of administration, high success rates, rapid onset and better muscle relaxation. ${ }^{1}$ This study carried out to observed the effect of addition of clonidine or dexmedetomidine to the local anaesthetic for haemodynamic stability in the intraoperatively ${ }^{2,3}$ analgesic affect in the postoperative period which allows for early ambulation.

\section{MATERIALS AND METHODS}

The study was done after approval of the ethical and screening committee of AGMC and GBP Hospital, Agartala; Tripura. All patients registered for abdominal hysterectomy surgeries belonging to ASA (American Society of Anaesthesiologists) grade I \& II, aged between $20-60$ years, height between $(145-165) \mathrm{cm}$. The patients for the study was categorized in three groups having $3.5 \mathrm{ml}$ solution for each. In first group for sub-arachnoid block, the local anaesthetic drug Bupivacaine heavy (0.5\%) $3 \mathrm{ml}$ mixed with 0.5 $\mathrm{ml}$ normal saline (Group B). In second group, Inj. Bupivacaine heavy (0.5\%) $3 \mathrm{ml}$ mixed with Clonidine $15 \mathrm{mcg}(0.5 \mathrm{ml})$ in normal saline (Group C). In the third group D, Inj. Bupivacaine heavy (0.5\%) $3 \mathrm{ml}$ mixed with Dexmedetomidine $10 \mathrm{mcg}(0.5 \mathrm{ml})$ in normal saline. The onset, duration, quality of analgesia was assessed and hemodynamic changes were monitored. Level of sensory nerve block was assessed bilaterally by touching the skin with wisp of cotton in the midclavicular line. Motor blockade was assessed by using the modified Bromage scale. Analysis was done by analysis of variance (ANOVA, chi-squared test or Fisher's exact test, post hoc test namely Tukey's HSD test as appropriate. The statistical analysis was done using SPSS version 15 software.

\section{RESULTS}

Time to 2 segment regression (D-144.38 vs. C-118. 98 vs. B-96.24) min. with p value $<0.0001$ ), regression time to $\mathrm{T}^{4}$ level (D170.38 vs. C- 153.84 vs. B-124.92) min. with p value< 0.0001 , Bromage score 0 (D-252.82 vs. C- 176.62 vs. B- 147.68) min. with $p$ value $<0.0001$ ) and $1^{\text {st }}$ analgesic request (D-197.72 vs. C-176.62 vs. B-147.68) min was significantly higher in group-D than group$\mathrm{C}$ and group-B. The duration of motor and sensory blockade was significantly higher $(\mathrm{p}<0.05)$ in Group $\mathrm{C}$ patients when compared to group B. The duration of motor blockade was highest in group D. The onset of sensory and motor block is not altered by addition of clonidine or dexmedetomidine. Compared to clonidine, dexmedetomidine significantly prolongs the duration of sensory and motor blockade. There is no significant increase of adverse effects when clonidine or dexmedetomidine is added to hyperbaric bupivacaine as intrathecal adjuvant.

\section{DISCUSSION}

Clonidine prolongs the duration of intrathecally administered local anaesthetics and has potent anti-nociceptive properties ${ }^{4,5,6}$ Clonidine administration, the intrathecal route is more effective in prolonging bupivacaine spinal anaesthesia. ${ }^{7}$.Animal studies ${ }^{8}$ have shown that affinity of dexmedetomidine to $\alpha_{2}$-adrenoceptor is 8 times more than clonidine. The onset of analgesia at T6 dermatomal level was earlier in the $\mathrm{D}$ group $(9.28 \pm 1.94)$ min as compared to the $C$ group $(10.04 \pm 1.69)$ min and B group $(9.46 \pm 1.94) \mathrm{min}$, but it was insignificant $\mathrm{P}=0.111$ (Table 1). Total of 29 patients in our study achieved peak sensory block of $\mathrm{T}_{4}$ level, 10 from group-B, 11 from group-C and 8 from group-D. However, most patient's i.e. 25 from group-B, 21 from group-C and 20 from group D, a total of 66 patients achieved peak sensory block level of T5 (Table 2) Time to maximum sensory block is mentioned as (11.20+/- 2.19) mins for B group and (11.45 +/- 1.80) mins for C groups and $(12.72+/-1.72)$ mins for D group (Table 3) and there was significant $(\mathrm{P}=0.018)$ difference of peak sensory block between the groups. The mean time to achieve onset of motor block (Bromage 3 motor block) in group-B was (7.02+/-2.05) minutes, in group-C was (7.06+/-1.81) mins and in group-D was (6.49+/-1.49) mins (Table 4). Time taken by our patients for 2 segment sensory regressions from the peak level in group-B was (96.24+/-7.40) mins, in group- C (118.98+/-6.40) mins and group D-(144.38+/-8.93) mins (Table 5) and the difference was statistically significant with $\mathrm{p}=<0.0001$. In group-B patients time for T10 segment regression was $(124.92+/-5.84)$ minutes, in group-C patients this time was higher (153.84+/-8.01) minutes and in group-D patients highest (170.38+/-6.87 minutes) (Table 6). Time taken to regain a Bromage score of 0 , was $(225.22+/-11.48)$ minutes on an average after spinal anaesthesia. In group-B patients (195.72+/-9.81) minutes to regain Bromage score 0, group-C patients $(227.14+/-10.75)$ minutes and group-D patients $(252.82+/-13.73)$ minutes (Table 7$)$ with $\mathrm{p}$ value of $<0.0001$. Our patients requested for their 1 st analgesic in group B- $(147.68+/-$ 10.11) minutes, group-C patients asked after (176.62+/-10.95) minutes but group-D patients requested for analgesic much later i.e. after (197.72+/-19.78) minutes (Table -8). This difference was significant with a very low p value of $<0.0001$. Mean heart rate in all groups were comparable over time as depicted by one way ANOVA test as all p values were $>0.05$ (Table-9). There was no fall or excess rise of heart rate in any group at any specific time period. The mean arterial pressure of all groups was comparable as shown by one way ANOVA analysis and all $p$ values were insignificant $(>0.05)$ (Table-10). There was no fall or rise of mean arterial 
pressure in any group intraoperatively or postoperatively. The oxygen saturation of different groups was almost identical with each other with high non-significant $p$ values as depicted by ANOVA (Table-11). The incidences of different side effects were low in the perioperative period up to a period of 6 hours and they were comparable between all the groups (Table 12). The data was compared with fisher's exact probability test: $2 * 3$ and p values were all very high i.e. Insignificant. As compared to group B, we found that the Group $C$ patients had prolonged motor and sensory blockade $(p<0.05)$. These results were similar to the findings reported by Seah YS et $\mathrm{al}^{9}$ and Racle JP et al ${ }^{10}$ in their studies done on patients who underwent TURP and orthopaedic surgeries respectively. In our study, the patients administered $10 \mu \mathrm{g}$ intrathecal dexmedetomidine reported longest duration of sensory and motor block and which is similar to the study Rampal Singh et al ${ }^{11}$ in 2012 . Gupta $\mathrm{R}$ et al ${ }^{12}$ compared the duration of motor and sensory blockade and haemodynamic stability dexmedetomidine with hyperbaric bupivacaine in patients who underwent lower abdominal surgeries and reported similar findings.

\section{CONCLUSION}

Clonidine and dexmedetomidine as intrathecal adjuvant significantly prolongs the sensory and motor blockade of intrathecal hyperbaric bupivacaine without altering the onset of spinal anaesthesia. In equipotent doses dexmedetomidine is more effective as intrathecal adjuvant to hyperbaric bupivacaine than clonidine. Neither clonidine nor dexmedetomidine increases side-effects of spinally administered hyperbaric bupivacaine if given in a low dose.

\section{KEYWORDS}

Subarachnoid Block, Bupivacaine, Clonidine, Dexmedetomidine.

HOW TO CITE THIS ARTICLE: Das SR, Reang R, Debnath J. A comparative study of sub-arachnoid block using intrathecal bupivacaine and intrathecal bupivacaine with low dose of either clonidine or dexmedetomidine in abdominal hysterectomy. J. Evolution Med. Dent. Sci. 2017;6(8):639-643, DOI: 10.14260/Jemds/2017/137

\section{BACKGROUND}

Lower abdominal and lower limb surgeries can be performed under general anaesthesia. However subarachnoid block has gained popularity because of its ease of administration, high success rates, quick onset and better muscle relaxation. ${ }^{1}$

Due to short duration of action of local anaesthetics number of adjuvants, such as clonidine, dexmedetomidine, midazolam, opioids, neostigmine and magnesium sulphate has been studied to prolong the effect of spinal anaesthesia. $2,3,13,14,15$ Clonidine and dexmedetomidine which are $\alpha 2$ adrenergic have been repeatedly demonstrated to prolong sensory and motor block when used intrathecally with local anaesthetics.2,3,16

The addition of clonidine or dexmedetomidine also allows for a reduction in the total dose of the local anaesthetic used, better hemodynamic stability in the intra-operative period ${ }^{2,3}$ analgesic affect in the post-operative period which allows for early ambulation. ${ }^{17,18}$

\section{MATERIALS AND METHODS}

The study was done after approval of the ethical and screening committee of AGMC and GBP Hospital, Agartala. Written and informed consent was obtained from the entire patient prior to procedure.

1. Study Design- This was single blinded randomized control trial study.

2. Study Area- The present study was conducted in the operative room and post anaesthesia care unit under department of Anaesthesiology AGMC \&GBP Hospital.

3. Study Population- Those patients who has undergone abdominal hysterectomy under spinal anaesthesia.

Financial or Other, Competing Interest: None.

Submission 07-11-2016, Peer Review 11-01-2017,

Acceptance 19-01-2017, Published 25-01-2017.

Corresponding Author:

Dr. Subhash Ranjan Das,

Department of Anaesthesiology,

AGMC, Agartala,

West Tripura.

E-mail: dr.sr_das@rediffmail.com

DOI: $10.14260 /$ jemds $/ 2017 / 137$

(c) $($ ) $\$$

\section{3a. Inclusion Criteria}

I. All patients registered for abdominal hysterectomy surgeries belonging to ASA (American Society of Anaesthesiologists) grade I \& II only.

II. Patient of female gender between 20 -60 years of age group. iii. Patients of height belonging to $145 \mathrm{~cm}$ to $165 \mathrm{~cm}$.

\section{3b. Exclusion Criteria}

I. Patients' refusal.

II. Patients using $\alpha 2$ (Alpha two) receptors antagonists, calcium channel blockers, angiotensin converting enzyme.

III. Patients with bleeding diatheses.

IV. Patients with psychiatric illness, neurologic diseases.

V. Patients belonging to the class ASA Physical status iii \& IV.

VI. Patients having history of hypersensitivity to anaesthetic agents.

4. Blinding- Single blinded, subjects was blinded about intervention.

\section{Technique}

All the patients selected for study were premedicated with Inj. Ondansetron $8 \mathrm{mg} \&$ Inj. Ranitidine $50 \mathrm{mg}$ intravenously prior to 2 hours of sub-arachnoid block. Preloaded with one litre of Ringer lactate solution thirty minutes prior to surgery. Base line parameters including blood pressure and E.C.G was recorded using multipara-monitors. The patients for the study was categorized in three groups having $3.5 \mathrm{ml}$ solution for each. In first group(B) Inj. Bupivacaine heavy (0.5\%) $3 \mathrm{ml}$ and $0.5 \mathrm{ml}$ normal saline. In second group(C) Inj. Bupivacaine heavy $(0.5 \%), 3 \mathrm{ml}$ mixed with Clonidine $15 \mathrm{mcg}$ in normal saline. In the third group (D), Inj. Bupivacaine heavy $(0.5 \%) 3$ $\mathrm{ml}$ mixed with Dexmedetomidine $10 \mathrm{mcg}$ in normal saline.

Sub-arachnoid block was given in midline sitting position in L3-L4 interspaces' under full aseptic and antiseptic precaution. Than turning the patient supine immediately. 
Onset of sensory, motor Blockade was noted. The ECG, HR, SPO2, NIBP and RR was continuously monitored and recorded till the completion of surgery. The onset, duration, quality of analgesia was noted and hemodynamic changes were monitored. Analgesic effect was assessed by pin-prick method. Sensory nerve block was assessed bilaterally by touching the skin with wisp of cotton in the midclavicular line. Motor blockade was assessed by using the modified Bromage scale.

\section{RESULTS AND ANALYSIS}

\begin{tabular}{|c|c|c|c|c|c|c|}
\hline \multirow{2}{*}{$\begin{array}{c}\text { Group-B } \\
(\text { Mean+/-Sd) }\end{array}$} & \multirow{2}{*}{$\begin{array}{c}\text { Group-C } \\
(\text { Mean+/-Sd) }\end{array}$} & \multirow{2}{*}{$\begin{array}{c}\text { Group-D } \\
(\text { Mean+/-Sd) }\end{array}$} & \multirow{2}{*}{\begin{tabular}{|l|} 
ANOVA \\
p value \\
\end{tabular}} & \multicolumn{3}{|c|}{ Tukey's HSD Test (Post-hoc test) } \\
\hline & & & & B vs. C & B vs. D & C vs. D \\
\hline $9.46+/-2.00$ & $10.04+/-1.69$ & $9.28+/-1.94$ & 0.111 & \multicolumn{3}{|c|}{ Not done } \\
\hline
\end{tabular}

The average time taken for intrathecal drug to achieve $\mathrm{T}_{6}$ level sensory block was 9.59+/- 1.87 minutes. When these parameters were compared with one-way ANOVA, there was no significant difference between the groups. However mean time to achieve $\mathrm{T}_{6}$ level sensory block in group-B was $9.46+/-2.00$ minutes, in group-C was $10.04+/-1.69$ minutes and in group-D was $9.28+/-1.94$ minutes.

Total of 29 patients in our study achieved peak sensory block of $\mathrm{T}_{4}$ level, 10 from group-B, 11 from group-C and 8 from groupD. However, most patient's i.e. 25 from group-B, 21 from group-C and 20 from group D, a total of 66 patients achieved peak sensory block level of $\mathrm{T}_{5}$.

\begin{tabular}{|c|c|c|c|c|c|c|}
\hline \multirow{2}{*}{$\begin{array}{c}\text { Group-B } \\
(\text { Mean+/-Sd) }\end{array}$} & \multirow{2}{*}{$\begin{array}{c}\text { Group-C } \\
(\text { Mean+/-Sd) }\end{array}$} & \multirow{2}{*}{$\begin{array}{c}\text { Group-D } \\
\text { (Mean+/-Sd) }\end{array}$} & ANOVA & \multicolumn{3}{|c|}{ Tukey's HSD Test (post-hoc test) } \\
\hline & & & p value & B vs. C & B vs. D & Cvs.D \\
\hline $7.02+/-2.05$ & $7.06+/-1.81$ & $6.94+/-1.49$ & 0.944 & \multicolumn{3}{|c|}{ Not done } \\
\hline
\end{tabular}

The average time taken for intrathecal drug to achieve Bromage 3 motor block was $7.006+/-1.783$ minutes. When these parameters were compared with one-way ANOVA, there was no significant difference between the groups. However mean time to achieve Bromage 3 motor block in group- $\mathrm{B}$ was $7.02+/-2.05$ minutes, in group- $\mathrm{C}$ was $7.06+/-1.81$ minutes and in group-D was $6.49+/-1.49$ minutes.

Time taken by patients for 2 sensory segment regressions from the peak level was $119.86+/-7.57$ minutes. In group-B patients time for 2 segment regression was $96.24+/-7.40$ minutes. In group-C patients this time was higher $(118.98+/-6.40$ minutes $)$ and in group-D patients highest (144.38+/-8.93 minutes). The difference was significant as shown by one way ANOVA and the $p$ value was $<0.0001$ which is very highly significant. Tukey's HSD test was applied as post hoc test and it showed significant difference between group-B and group-C, group-B and group-D, and group-C and group-D. In all cases p value was $<0.01$ which was highly significant. So it can be said that both clonidine and dexmedetomidine prolongs the 2 segment regression time but dexmedetomidine is superior in prolonging 2 segment regression time.

Time taken by our patients to regress up to T10 level from the peak level was $149.71+/-6.90$ minutes. In group-B patients time for T10 segment regression was 124.92+/-5.84 minutes. In group-C patients this time was higher $(153.84+/-8.01$ minutes) and in group-D patients highest (170.38+/-6.87 minutes). The difference was significant as shown by one way ANOVA and the $p$ value was $<0.0001$ which is very highly significant. Tukey's HSD test was applied as post hoc test and it showed significant difference between group-B and group-C, group-B and group-D, and group-C and group-D. In all cases p value was $<0.01$ which was highly significant. So, it can be said that both clonidine and dexmedetomidine prolongs the T10 segment regression time but dexmedetomidine is superior in prolonging T10 segment regression time.

\begin{tabular}{|c|c|c|c|c|c|c|c|c|c|}
\hline \multicolumn{2}{|c|}{ Group-B } & \multicolumn{2}{c|}{ Group-C } & \multicolumn{2}{c|}{ Group-D } & p value & B vs. C & B vs. D & C vs. D \\
\hline Mean & Std. Dev. & Mean & Std. Dev. & Mean & Std. Dev. & ANOVA & \multicolumn{1}{c|}{ Tukey's HSD Test (Post-hoc test) } \\
\hline 195.72 & 9.18 & 227.14 & 10.75 & 252.82 & 13.73 & $<0.000$ & $<0.01$ & $<0.01$ & $<0.01$ \\
\hline \multicolumn{8}{|c|}{ Table 3. Time to Regress to Bromage 0 Motor Block } \\
\hline
\end{tabular}

To regain a Bromage score of 0 , our patients took $225.22+/-11.48$ minutes on an average after spinal anaesthesia. Group-B patients took 195.72+/-9.81 minutes to regain Bromage score 0, group-C patients took 227.14+/-10.75 minutes and group-D patients took $252.82+/-13.73$ minutes. One way ANOVA done and p value was $<0.0001$. So, the difference is very highly significant. Tukey's HSD test done as a post hoc test and differences between all groups were significant. So, group-C patients took significantly longer time than group-B patients to regain Bromage 0 score. And group-D patients took significantly longer time than group- B and group-C patients to regain Bromage 0 score. So, motor blockade was also prolonged in dexmedetomidine group than in clonidine group.

\begin{tabular}{|c|c|c|c|c|c|c|c|c|c|}
\hline \multicolumn{2}{|c|}{ Group-B } & \multicolumn{2}{c|}{ Group-C } & \multicolumn{2}{c|}{ Group-D } & p value & B vs. C & B vs. D & C vs. D \\
\hline Mean & Std. Dev & Mean & Std. Dev & Mean & Std. Dev & ANOVA & \multicolumn{2}{|c|}{ Tukey's HSD Test (Post-hoc test) } \\
\hline 147.68 & 10.11 & 176.62 & 10.95 & 197.72 & 19.78 & $<0.0001$ & $<0.01$ & $<0.01$ & $<0.01$ \\
\hline \multicolumn{8}{|c|}{ Table 4. Time to 1st Analgesic Request (Min.) } \\
\hline
\end{tabular}


On an average our patients requested for their 1st analgesic 174.02+/-13.61 minutes after the spinal anaesthesia. Group-B patients asked after 147.68+/-10.11 minutes, group-C patients asked after 176.62+/-10.95 minutes but group-D patients requested for analgesic much later i.e. after 197.72+/-19.78 minutes. When compared with one way ANOVA this difference was significant with a very low $\mathrm{p}$ value of $<0.0001$. When Tukey's HSD test was applied that time taken by group-C was significantly higher than time taken by group-B with a $\mathrm{p}$ value of $<0.01$. Again, time taken by group-D patients was also significantly higher than both group-B ( $p$ value- $<0.01$ ) and group-C ( $p$ value- $<0.01$ ). So, the inference would be that both dexmedetomidine and clonidine increases the time of post-operative analgesia but dexmedetomidine do more so.

Mean heart rate in all groups were comparable over time as depicted by one way ANOVA test as all $p$ values were $>0.05$. There was no fall or excess rise of heart rate in any group at any specific time.

\begin{tabular}{|c|c|c|c|c|c|c|c|}
\hline \multirow{2}{*}{ Time (Min) } & \multicolumn{2}{|c|}{ Group B } & \multicolumn{2}{c|}{ Group C } & \multicolumn{2}{c|}{ Group D } & \multirow{2}{*}{$\begin{array}{c}\text { p value } \\
\text { ANOVA }\end{array}$} \\
\cline { 2 - 7 } & Mean & Std. Dev & Mean & Std. Dev & Mean & Std. Dev & 0.137 \\
\hline 0 & 93.8 & 8.75 & 92.16 & 6.05 & 90.92 & 6.50 & 0.061 \\
\hline 3 & 92.98 & 6.38 & 91.2 & 5.31 & 90.2 & 5.97 & 0.107 \\
\hline 6 & 88.83 & 4.94 & 88.74 & 4.64 & 86.98 & 5.10 & 0.160 \\
\hline 9 & 87.02 & 4.77 & 86.5 & 4.35 & 85.3 & 4.61 & 0.122 \\
\hline 12 & 85.68 & 4.47 & 84.92 & 3.92 & 83.86 & 4.84 & 0.106 \\
\hline 15 & 85.42 & 4.18 & 85.42 & 3.65 & 82.78 & 3.81 & 0.601 \\
\hline 20 & 81.46 & 3.66 & 80.92 & 3.18 & 80.66 & 5.04 & 0.061 \\
\hline 30 & 78.6 & 4.63 & 76.8 & 3.03 & 77.76 & 3.49 & 0.063 \\
\hline 45 & 79.18 & 4.52 & 77.42 & 3.63 & 78.84 & 3.74 & 0.069 \\
\hline 60 & 81.12 & 4.99 & 80.55 & 3.92 & 79.2 & 3.27 & 0.082 \\
\hline 90 & 82.54 & 4.68 & 81.7 & 3.33 & 80.8 & 3.60 & 0.073 \\
\hline 120 & 83.72 & 3.87 & 82.1 & 3.57 & 83.6 & 4.20 & 0.983 \\
\hline 150 & 85.98 & 4.91 & 84.98 & 3.02 & 84.2 & 4.07 & 0.518 \\
\hline 180 & 87.08 & 4.51 & 86.76 & 4.08 & 86.12 & 4.16 & 0.178 \\
\hline 240 & 89.22 & 4.82 & 88.54 & 4.66 & 87.44 & 4.94 & 0.097 \\
\hline 300 & 92.46 & 5.52 & 90.22 & 4.52 & 90.72 & 6.05 & 0.786 \\
\hline 360 & 88.36 & 4.53 & 87.74 & 4.02 & 88.06 & 4.81 & \\
\hline \multicolumn{7}{|c|}{ Table 5. Mean Arterial Pressure (mmH) } \\
\hline
\end{tabular}

The mean arterial pressure of all groups was comparable as shown by one way ANOVA analysis and all p values were insignificant $(>0.05)$. There was no fall or rise of mean arterial pressure in any group intraoperatively or postoperatively.

So, it can be said that both clonidine and dexmedetomidine preserve hemodynamic stability.

The oxygen saturation of different groups was almost identical with each other with high non-significant $p$ values as depicted by ANOVA, it can be concluded that there was no hemodynamic and respiratory problem in any group.

\begin{tabular}{|c|c|c|c|c|}
\hline & Group-B & Group-C & Group-D & p value \\
\hline Bradycardia & 3 & 6 & 3 & 1 \\
\hline Hypotension & 2 & 5 & 3 & 1 \\
\hline Nausea \& Vomiting & 3 & 3 & 2 & 1 \\
\hline Pruritus & 0 & 0 & 0 & 0 \\
\hline Respiratory depression & 0 & 0 & Table 6. Incidences of Side Effects \\
\hline
\end{tabular}

The incidences of different side effects were low in the perioperative period up to a period of 6 hours and they were comparable between all the groups. The data was compared with fisher's exact probability test: $2 * 3$ and p values were all very high i.e. Insignificant.

\section{DISCUSSION}

The intrathecal route of clonidine is more effective in prolonging bupivacaine spinal anaesthesia. ${ }^{7}$ Animal studies ${ }^{8}$ have shown that affinity of dexmedetomidine to $\alpha_{2}$ adrenoceptor is 8 times more than clonidine. The onset of analgesia at T6 dermatomal level was earlier in the D group (9.28 \pm 1.94$) \mathrm{min}$ as compared to the $\mathrm{C}$ group $(10.04 \pm 1.69)$ min and B group $(9.46 \pm 1.94) \mathrm{min}$, but it was insignificant $\mathrm{P}=0.111$ (Table 1). Total of 29 patients in our study achieved peak sensory block of $\mathrm{T}_{4}$ level, 10 from group-B, 11 from group-C and 8 from group-D. However, most patient's i.e. 25 from group-B, 21 from group-C and 20 from group D, a total of 66 patients achieved peak sensory block level of T5. Time to maximum sensory block is mentioned as $(11.20+/-2.19)$ mins for B group and (11.45 +/- 1.80) mins for C groups and $(12.72+/-1.72)$ mins for $D$ group and there was significant $(\mathrm{P}=0.018)$ difference of peak sensory block between the groups. The mean time to achieve onset of motor block (Bromage 3 motor block) in group-B was $(7.02+/-2.05)$ minutes, in group-C was $(7.06+/-1.81)$ mins and in group-D was $(6.49+/-1.49)$ mins (Table 2). Though the time of onset of motor block was less in Group D, there was no statistical significant difference in three groups $(\mathrm{p}=0.944)$. Time taken by our patients for 2 segment sensory regressions from the peak level in group-B was $(96.24+/-7.40)$ mins, in group- $C$ (118.98+/-6.40) mins and group D-(144.38+/-8.93) mins and the difference was statistically significant with $\mathrm{p}=<0.0001$. In group- $\mathrm{B}$ patients time for $\mathrm{T} 10$ segment regression was $(124.92+/-5.84)$ minutes, in group-C patients this time was higher (153.84+/-8.01) minutes and in group-D patients highest (170.38+/-6.87 minutes). The difference was significant with $\mathrm{p}$ value of $<0.0001$ which is very highly 
significant. Time taken to regain a Bromage score of 0 , was (225.22+/-11.48) minutes on an average after spinal anaesthesia. In group-B patients $(195.72+/-9.81)$ minutes to regain Bromage score 0, group-C patients $(227.14+/-10.75)$ minutes and group-D patients $(252.82+/-13.73)$ minutes (Table 3 ) with $p$ value of $<0.0001$. Our patients requested for their 1st analgesic in group B- $(147.68+/-10.11)$ minutes, group-C patients asked after $(176.62+/-10.95)$ minutes but group-D patients requested for analgesic much later i.e. after (197.72+/-19.78) minutes. This difference was significant with a very low $p$ value of $<0.0001$.

Mean heart rate in all groups were comparable over time as depicted by one way ANOVA test as all $p$ values were $>0.05$. There was no fall or excess rise of heart rate in any group at any specific time period.

The mean arterial pressure of all groups was comparable as shown by one way ANOVA analysis and all $p$ values were insignificant $(>0.05)$ (Table-5). There was no fall or rise of mean arterial pressure in any group intraoperatively or postoperatively. The incidences of different side effects were low in the perioperative period up to a period of 6 hours and they were comparable between all the groups Table (6). The data was compared with Fisher's exact probability test: $2 * 3$ and $p$ values were all very high i.e. Insignificant. As compared to group B, we found that the Group C patients had prolonged motor and sensory blockade $(\mathrm{p}<0.05)$. These results were similar to the findings reported by Seah YS et al ${ }^{9}$ and Racle JP et $\mathrm{al}^{10}$ in their studies done on patients who underwent TURP and orthopaedic surgeries respectively. In the present study, the patients administered $10 \mu \mathrm{g}$ intrathecal dexmedetomidine reported longest duration of sensory and motor block and which is similar to the study Rampal Singh et $\mathrm{al}^{11}$ in 2012. They compared intrathecal clonidine and dexmedetomidine with intrathecal hyperbaric bupivacaine and concluded that though both clonidine and dexmedetomidine prolonged duration of sensory and motor block of bupivacaine, dexmedetomidine is better in terms of longer duration of action. Gupta $\mathrm{R}$ et $\mathrm{al}^{12}$ compared the duration of motor and sensory blockade and haemodynamic stability dexmedetomidine with hyperbaric bupivacaine in patients who underwent lower abdominal surgeries and reported similar findings.

\section{REFERENCES}

[1] Birnbach DJ, Browne IM. Anesthesia for obstetrics. In: Miller RD, Eriksson LI, Fleisher LA, et al. (eds) Miller's anesthesia. $7^{\text {th }}$ edn. Chapter 69. Philadelphia, Churchill Livingstone Elsevier Inc 2010:p 2219.

[2] Kanazi GE, Aouad MT, Jabbour-Khoury SI, et al. Effect of low-dose dexmedetomidine or clonidine on the characteristics of bupivacaine spinal block. Acta Anaesthesiol Scand 2006;50(2):222-7.

[3] Elia N, Culebras X, Mazza C, et al. Clonidine as an adjuvant to intrathecal local anaesthetics for surgery: systematic review of randomized trials. Reg Anesth Pain Med 2008;33(2):159-67.
[4] Liu S, Chiu AA, Neal JM, et al. Oral clonidine prolongs lidocaine spinal anaesthesia in human volunteers. Anaesthesiology 1995;82(6):1353-9.

[5] Ota K, Namiki A, Iwasaki $H$, et al. Dose-related prolongation of tetracaine spinal anaesthesia by oral clonidine in humans. Anesth Analg 1994;79(6):11215.

[6] Rhee $\mathrm{K}$, Kang K, Kim J, et al. Intravenous clonidine prolongs bupivacaine spinal anaesthesia. Acta Anaesthesiol Scand 2003;47(8):1001-5.

[7] Bonnet F, Buisson VB, Francois Y, et al. Effects of oral and subarachnoid clonidine on spinal anaesthesia with bupivacaine. Regional Anaesthesia 1990;15(4):211-4.

[8] Asano T, Dohi S, Ohta S, et al. Antinociception by epidural and systemic $\alpha 2$ adrenoreceptor agonists and their binding affinity in rat spinal cord and brain. Anesth Analg 2000;90(2):400-7.

[9] Seah YS, Chen C, Chung KD, et al. Prolongation of hyperbaric bupivacaine spinal anaesthesia with clonidine. Ma Zui Xue Za Zhi 1999;29(1):533-7.

[10] Racle JP, Benkhadra A, Poy JY, et al. Prolongation of isobaric bupivacaine spinal anaesthesia with epinephrine and clonidine for hip surgery in the elderly. Anesth Analg 1987;66(5):442-6.

[11] Singh R, Shukla A. Randomized, controlled study to compare the effect of intrathecal clonidine and dexmedetomidine on sensory analgesia and motor block of hyperbaric bupivacaine. Indian Journal of Fundamental And Applied Life Sciences 2012;2(4):2433.

[12] Gupta R, Verma R, Bogra J, et al. A comparative study of intrathecal dexmedetomidine and fentanyl as adjuvants to bupivacaine. J Anaesthesiol Clin Pharmacol 2011;27(3):339-43.

[13] Boussofara $M$, Carlès $M$, Raucoules-Aimé $M$, et al. Effects of intrathecal midazolam on postoperative analgesia when added to a bupivacaine-clonidine mixture. Reg Anesth Pain Med 2006;31(6):501-5.

[14] Elizabeth A, Hamber, Christopher M. Intrathecal lipophilic opioids as adjuncts to spinal anaesthesia. Regional Anaesthesia and Pain Medicine 1999;24(3):255-63.

[15] Spencer S, Liu. Drugs for spinal anaesthesia: past, present, and future. Regional Anesthesia and Pain Medicine 1998;23(4):344-6.

[16] Stoelting RK, Simon HC. Pharmacology \& physiology in anaesthetic practice. $4^{\text {th }}$ edn. Chapter 3 , Philadelphia: Lippincott Williams \& Wilkins 2006:90-1.

[17] Gupta R, Bogra J, Verma R, et al. Dexmedetomidine as an intrathecal adjuvant for postoperative analgesia. Indian J Anaesth 2011;55(4):347-51.

[18] Axelsson K, Gupta A. Local anesthetic adjuvant: neuraxial versus peripheral nerve block. Curr Opin Anaesthesiol 2009;22(5):649-54. 